\title{
Resource location in problem solving groups made up of married couples, friends, and strangers'
}

\author{
Thomas J. Banta, UNIVERSITY OF DENVER \\ Herbert Horowitz, AMERICAN INSTITUTE FOR RESEARCH
}

\begin{abstract}
Probability of opinion adoption and participation in problem solving was studied as a function of the type of social relationship between the pair of Ss (married couples, friends, and strangers) and as a function of $E^{\prime}$ 's favoring the opinions of the male or the female in the pair through experimentally controlled success and failure feedback. The results showed that type of social relation and feedback were important in determining the ability of the pair to detect the experimentally allocated problem solving resources of the members. Malefavored married couples and male-favored friends were superior to the other treatments in locating these resources.
\end{abstract}

\section{Problem}

In the present study the experimental procedures of Banta \& Nelson (1964) were extended to heterosexual pairs of Ss and three types of social relationships (married couples, friends, and strangers). It was expected (1) that base rate dominance of the male would vary as a function of the type of social relationship, and (2) that here would be differential changes as a result of success and failure feedback as a function of both the type of social relationship and of male-favored and female-favored conditions of feedback.

As in the Banta \& Nelson experiment the stated problem was to jointly predict the personality responses of a third person. The unstated problem was that of resource location. Resource location is defined as the group process of finding out who has the best ideas in the solution of a problem. In this experiment the pair of Ss had to develop a style of interaction which enabled an $\mathrm{S}$ to get his opinion adopted in order to get correct
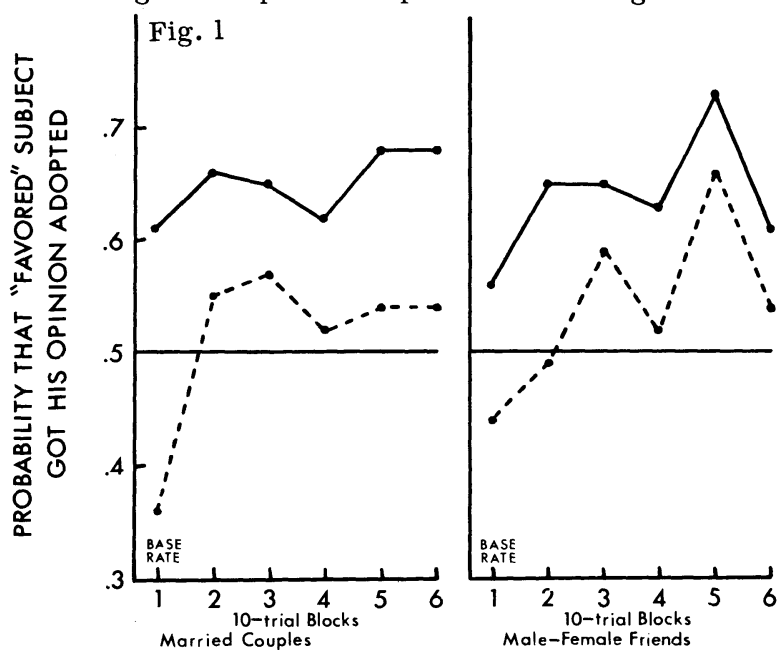

Male-Female Friends feedback from the differentially favoring task environment, regardless of any irrelevant status differences or personal needs of the Ss.

\section{Method}

Sixty male-female pairs of Ss were used. All Ss were recruited from a population of residents in the married student apartments at the University of Wisconsin. Twenty married couples constituted the first experimental condition. The second condition was made up of 20 male-female friendship pairs. Half of the friends were selected by the male of the pair, half were selected by the female. The only restriction on this choice was that the friend be chosen from the University apartment residents, to insure that all Ss were drawn from the same pool of married couples. The third condition, 20 pairs of strangers, was arranged by $\mathrm{E}$ on a randombasis, with the restriction a given pair of Ss had not met previously or talked to one another in the past.

E seated the pair at a table in the experimental room. In front of them was a one-way mirror. On the table were two microphones and their response panel. Their job was to predict the responses of a "mental patient" to an attitude test on the basis of their knowledge of his first five answers alone. The joint decisions were indicated on a response panel by flipping a switch under one of the six alternative labels located at the top of the panel: Strongly Agree, Agree, Slightly Agree, Slightly Disagree, Disagree, and Strongly Disagree. There were 60 such predictions, each constituting an experimental trial. The first 10 trials were base rate trials during which no right or wrong feedback was given. During the last 50 trials a light labeled "right" was turned on by $\mathrm{E}$ with a probability of .7 if the favored person got his opinion adopted. Otherwise the light labeled "wrong" was turned on. This is referred to as a $70 \%-0 \%$ schedule. In the event that both Ss suggested the same opinion, the person suggesting it first was considered to have gotten his opinion adopted. Details of experimental and observational procedure are given in Banta \& Nelson (1964) and Banta (1963).

In half the experimental pairs of Ss, success feedback was given $70 \%$ of the time when the male got his opinion adopted, and in half the pairs success feedback was given $70 \%$ of the time when the female got her opinion adopted. Thus there were six independent experimental conditions, with three types of social relationships and two methods of favoring (male-favored and female-favored schedules).

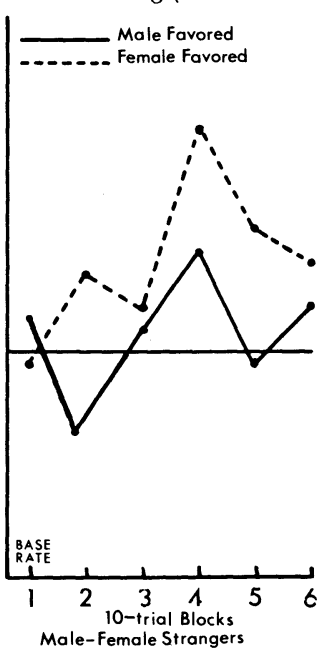

\section{Results}

Figure 1 shows the probability of the favored S's getting an opinion adopted as a function of 10-trial blocks and the type of social relationship. This probability was based on the average percent of adoptions of the favored S's opinions in each block of 10 trials. Each curve was based on data from 10 malefemale pairs of Ss.

Males were dominant during the non-feedback, base rate period in the married couples condition $(p<.005)$, less so in 
the friends condition $(.05<\mathrm{p}$ $<.10)$, and not all in the strangers condition. (All statistical tests are two-tailed $\mathrm{t}$ tests.)

Under the 70\%-0\% feedback conditions in trials 11 through 60 , the males got significantly more opinions adopted in the married couples condition ( $p$ $<.005)$, as well as in the friends condition $(p<.01)$, but in the strangers condition the dominance was reversed; females got significantly more opinions adopted $(.01<\mathrm{p}<.025)$.

Participation in making opinion proposals is shown in Fig. 2, separating favored and non-favored Ss in Fig. 2, for each type of social relationship. In the base rate periods, only the husbands in the married couples condition were significantly

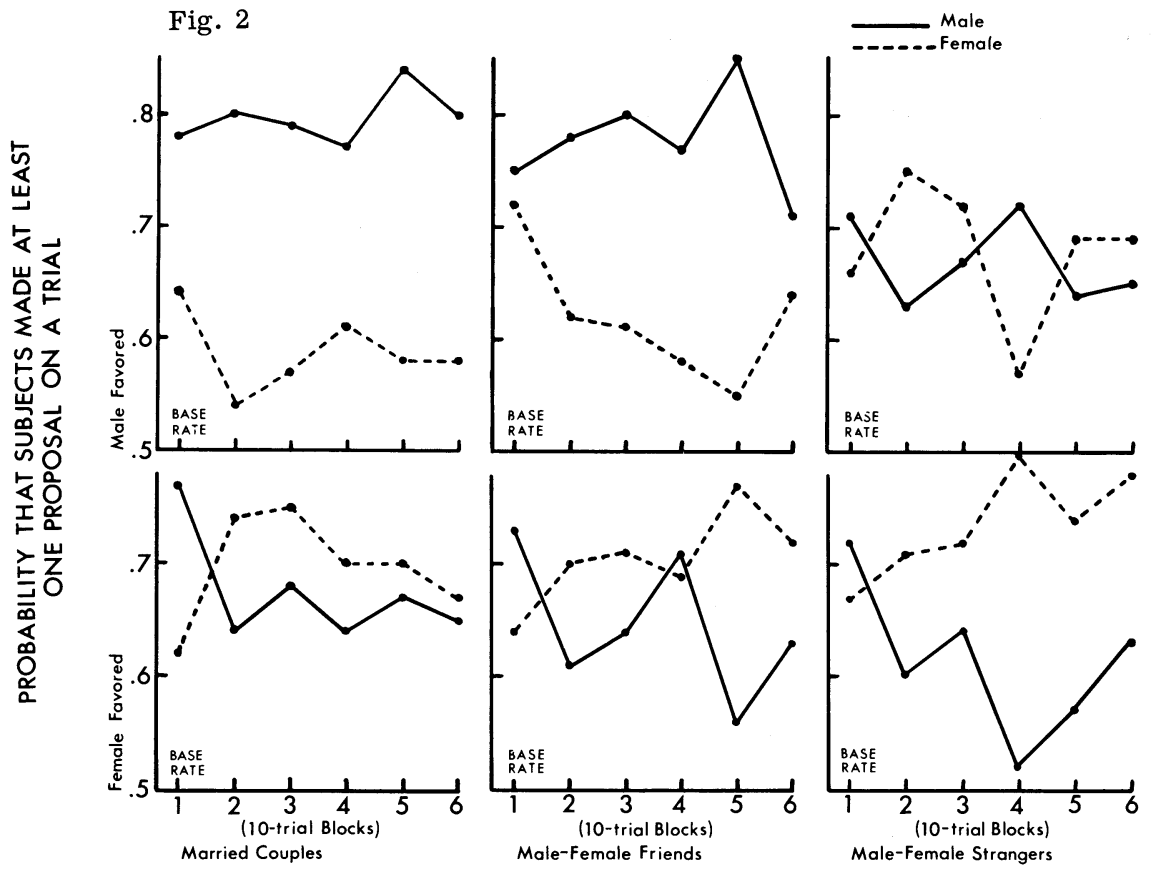
greater participators $(p<.01)$, although the males were numerically greater participators than females in all conditions.

During the feedback period, favored males participated more than favored females in the married and friends conditions $(p<.005$, and $p<.05$, respectively); but in the strangers condition favored females participated more than favored males $(p<.005)$. This parallels the opinion adoption data for the feedback period, given above. A similar pattern holds for the non-favored Ss, with non-favored husbands participating more than nonfavored wives $(p<.05)$, no differences for friends, but non-favored females participating more than non-favored males in the strangers condition $(p<.025)$. Thus husbands tended to participate more whether favored or not, and females in the stranger condition tended to participate more whether favored or not.

Another way of looking at these same data is in terms of dominance within the pair. Favored husbands participated more than their non-favored wives $(p<.02)$; favored male friends participated more than their female partners $(p<.01)$; and there was no male dominance at all in the strangers condition. This trend was completely reversed in the female favored conditions with greatest female dominance in the stranger condition $(p<.05)$, less so for the friends condition $(p<.30)$, and still less wife dominance over her husband (p, n.s.).

\section{Discussion}

In the context of the resource location theory proposed by Banta \& Nelson the present data can be ordered for the optimal social relationships and task environment combinations which enabled pairs of Ss to locate the source of valid opinions in their problem solving group. The male favored marriage relationship was superior, followed closely by the male favored friends relation-

ship. The female favored strangers condition showed good use of feedback even though starting from an equalitarian base rate. The remaining two female favored conditions (married and friends) showed significant gains for the female but they do not completely overcome the base rate handicap; resource location improved, but it was not optimized relative to male favored married couples and strangers. Finally, the male favored stranger condition was weakest in locating resources and in developing an efficient participation pattern.

The success and failure feedback arrangements used in this experiment may be viewed as ecological settings within which problem solving groups functioned. Thus, in the setting which favored the opinion resources provided by the male, a male-dominant relationship assured that rewards were forthcoming from the environment, greater than would be expected if the relationship were equalitarian. Dominance can therefore be functional in some settings, but in others it can bedysfunctional; the task environment must be taken into account.

\section{References}

BANTA, T. J. Aggregate reinforcement of free social interaction. Paper read at the Wisconsin Conference on Experimental Analyses of Social interaction, August 19-23, 1963, Madison, Wisconsin. BANTA, T. J., \& NELSON, C. Experimental analysis of resource location in problem solving groups. Sociometry, 1964, in press. Note

1. This research was supported by Grants M-6033 and M-8658 from the National Institutes of Mental Health. The authors wish to thank Professor Eileen Mavis Hetherington for her help in designing the research and Miss Nancy Fahlberg for her help in running the experiment. 